\title{
IN SILICO MOLECULAR MODELING AND DOCKING STUDIES OF HERBAL COMPOUND MEDIATED INHIBITION OF K $\beta$ KINASE $\beta$ (INHIBITOR OF K $\beta$ KINASE SUBUNIT $\beta$ ) FOR OSTEOARTHRITIS TREATMENT
}

\author{
BASKARAN SUBRAMANI* \\ Department of Biomedical Science, Bharathidasan University, Tiruchirappalli, Tamil Nadu, India. Email: baskaranbms@gmail.com
}

Received: 04 December 2017, Revised and Accepted: 13 January 2018

\section{ABSTRACT}

Objective: This study was intended to investigate and characterize the phytoconstituents of plant herbs and inhibitors, evaluate its anti-osteoarthritis $(\mathrm{OA})$ and anti-inflammatory potential under in silico conditions.

Methods: Docking studies were performed to find out the maximum interaction between design ligands and selected five proteins using Schrodinger Software NY. Structures of selected proteins were downloaded from protein data bank.

Results: Morin, salubrinal, icariin, and chondroitin sulfate, and sesamol have higher binding energy than other compounds. Based on these properties out of 9 compounds we have selected 5 best-docked and compounds selected were molecular dynamics simulation with inhibitor of $\kappa \beta$ kinase subunit (IKK) ß. Arg20, Leu21, Thr23, Lys44, Glu61, Glu97, Cys99, Lys106, Asp145, Asn150, andAsp166 were actively involved in H-bond interaction with ligands. Each compound has different binding modes, which reflects the difference of interacting residues with different functional groups. Morin has better interaction than other compounds. Either Cys99 or Lys44 found predominantly in most of the complex except in $\beta$-ecdysterone whereas both found interacting with morin.

Conclusion: The results revealed out that the herbal compounds can inhibit the IKK $\beta$ protein. The virtual screening yielded five potential IKK $\beta$ inhibitors: Morin, salubrinal, icariin, and chondroitin sulfate, and sesamol. This inhibitor shows good interaction, energy, and pharmacophoric activity and will be suitable for further experiments of an anti-OA target.

Keywords: Docking studies, Nuclear factor kappa $\beta$, Herbal medicine, Osteoarthritis, Inhibitor of $\kappa \beta$ kinase subunit $\beta$.

(c) 2018 The Authors. Published by Innovare Academic Sciences Pvt Ltd. This is an open access article under the CC BY license (http://creativecommons. org/licenses/by/4. 0/) DOI: http://dx.doi.org/10.22159/ajpcr.2018.v11i4.24128

\section{INTRODUCTION}

Osteoarthritis (OA), the most common of joint diseases, is characterized by a progressive loss of articular cartilage and inflammation of synovium. Chondrocytes, the resident cells in articular cartilage, play an important role in cartilage degradation in OA [1]. Previous studies showed that inflammatory cytokines were involved in the pathogenesis of OA. Stimulating of chondrocytes by interleukin (IL)$1 \beta$ lead to the production of matrix metalloproteinases (MMPs) and other inflammatory mediators such as nitric oxide and prostaglandin (PGE)2 [2,3]. Nuclear factor kappa $\beta(\mathrm{NF \kappa} \beta)$ in synovial lining cells, in fibroblast-like synoviocytes and also in chondrocytes of subjects affected by $\mathrm{OA}$. NFK $\beta$ is responsible for the induction of the transcription of genes encoding pro-inflammatory cytokines such as IL1 $\beta$ and tumor necrosis factor (TNF) $\alpha$, enzymes such as cyclo-oxygenase- 2 that generate pro-analgesic mediators such as PGE2 as well as cartilagedegrading enzymes, e.g., the metalloproteinase (MMP-1, 3, and 13). These cytokines stimulate the production of degradative enzymes such as MMPs in cartilage, which is responsible for excessive cartilage matrix degradation in arthritis [4].

The nuclear transcription factor $N F \kappa \beta$ has a central role in the autoimmune, inflammatory, and destructive mechanisms that drive the progression of $\mathrm{OA}$. Normally, $\mathrm{NF} \kappa \beta$ is held in an inactive state in the cytoplasm by I $\kappa$ inhibitory proteins. In response to specific external stimuli, including TNF $\alpha$ and IL-1, the inhibitor of $\kappa \beta$ (Ік $\beta$ ) component of the complex is phosphorylated and degraded, resulting in the translocation of $\mathrm{NF \kappa} \beta$ into the nucleus and induction of gene transcription. The signal-induced phosphorylation of IкB involves two IкB kinases, IкB kinase subunit (IKK) $\alpha$ and IKK $\beta$. Various studies indicate that IKK $\beta$ plays the dominant role in the pro-inflammatory signal-induced phosphorylation of the I $\kappa$ B protein. On the other hand, IKK $\alpha$ is dispensable for these functions but is essential for developing the epidermis and its derivatives. IKK $\beta$ has been found to be responsible for some of the observed anti-inflammatory properties of marketed drugs such as aspirin and salicylates. Nowadays, the drugs used for the treatment of $\mathrm{OA}$ such as nonsteroidal anti-inflammatory drugs have numerous side effects. Therefore, it is urgently needed to seek safe and effective drugs to treat OA [5-7].

These target strategies only to affected cartilage and joints to avoid other undesirable systemic effects. In this paper, docking the IKK $\beta$ has been described as a targeted by herbal compounds and inhibitors are Morin [8], Salubrinal [9], Icariin [10], chondroitin sulfate [11], sesamol [12], delphinidin [13], LBH589 [14], thymoquinone [15], and $\beta$-ecdysterone [16], which appeared well suitable to treat OA diseases.

\section{METHODS}

\section{System configuration}

All the research works were carried out on a high-performance workstation operated with Cent OS Version-6.5 Linux operating platform. Hardware specifications are high-performance computing workstation running with Intel Core i7 processor of 8 Cores and $16 \mathrm{~GB}$ RAM speed. Software specifications used are the commercial version of Schrödinger Software package, LLC, New York, NY 2015.

\section{Protein and ligand preparation}

The crystal structure of target protein Human IкB kinase beta (IKK $\beta$ ), (protein data bank [PDB] ID: 4KIK) was retrieved from PDB [17]. The 
typical structure file from the PDB is not suitable for immediate use in molecular modeling calculations, and so the crystal structure of IKK $\beta$ was prepared through protein preparation wizard, implemented in Maestro 10.4 [18]. Missing residues were added using the prime loop modeling, which is also embedded in protein preparation wizard. First, the bond orders were assigned, hydrogen atoms were added, and all the crystallographic waters molecules were removed. The processing script optimizes the hydrogen-bonding network, rotating hydroxyl and thiol hydrogen, generating appropriate protonation and tautomerization states of His, and performing chi flips in Asn, Gln, and His residues. Optimized structure of IKK $\beta$ was minimized using optimized potentials for liquid simulations (OPLS)-2005 force field until the average root-mean-square deviation (RMSD) of the non-hydrogen atoms reached $0.3 \AA$

\section{Molecular docking}

The docking protocol was carried out using glide [19-21]. It performs grid-based ligand docking with energetic and searches for favorable interactions between one or more typically small ligand molecules and a typically larger receptor molecule, usually a protein. After ensuring that the protein and ligands were in the correct form for docking, the receptor-grid files were generated using a grid-receptor generation program. In this study, the grid was generated by using the predicted active site through the sitemap. Ligand docking panel was used to carry out the docking of all ligands of different charge. The receptor grid generated file was uploaded, and the precision extra precision (XP) was selected. Glide score was generated based on the following formula.

GScore $=a * v d W+b *$ Coul+Lipo + Hbond + Metal+BuryP+RotB+Site.

Where, $\mathrm{vdW}=$ van der Waal energy, $\mathrm{Coul}=$ Coulomb energy, Lipo=lipophilic contact term, Hbond=hydrogen-bonding term, Metal=metal-binding term, BuryP=penalty for buried polar groups, RotB=penalty for freezing rotatable bonds, and Site=polar interactions at the active site.

\section{Binding free energy calculation}

The free energy of binding was calculated using prime MM-GB/SA approach [22]. In this approach, the docked poses were minimized using the local optimization feature in Prime, and the energies of the complex were calculated using the OPLS-AA (2005) force field and generalized-born/surface area (GB/SA) continuum solvent model. The free energy of binding, $\Delta \mathrm{G}_{\text {bind }}$ is calculated as [23,24],

$\Delta \mathrm{G}_{\text {bind }}=\Delta \mathrm{E}+\Delta \mathrm{G}_{\text {solv }}+\Delta \mathrm{G}_{\mathrm{SA}}$

$\Delta \mathrm{E}=\mathrm{E}_{\text {complex }}-\mathrm{E}_{\text {protein }}-\mathrm{E}_{\text {ligand }}$

Where, $\mathrm{E}_{\text {complex' }}, \mathrm{E}_{\text {protein' }}$ and $\mathrm{E}_{\text {ligand }}$ are the minimized energies of the protein-ligand complex, protein, and ligand, respectively. Prime uses a surface generalized born model employing a Gaussian surface instead of a van der Waals surface for better representation of the solventaccessible SA.

$\Delta \mathrm{G}_{\text {solv }}=\mathrm{G}_{\text {solv }}($ complex $)-\mathrm{G}_{\text {solv }}$ (protein) $-\mathrm{G}_{\text {solv }}$ (ligand)

Where, $\mathrm{G}_{\text {solv }}$ (complex), $\mathrm{G}_{\text {solv }}$ (protein), and $\mathrm{G}_{\text {solv }}$ (ligand) are the solvation free energies of the complex, protein, and ligand, respectively.

$\Delta \mathrm{G}_{\mathrm{SA}}=\mathrm{G}_{\mathrm{SA}}($ complex $)-\mathrm{G}_{\mathrm{SA}}$ (protein) $-\mathrm{G}_{\mathrm{SA}}$ (ligand)

Where, $\mathrm{G}_{\mathrm{SA}}$ (complex), $\mathrm{G}_{\mathrm{SA}}$ (protein), and $\mathrm{G}_{\mathrm{SA}}$ (ligand) are the SA energies for the complex, protein, and ligand, respectively. The rational criteria for selection of best compounds based on scoring and interaction parameters shown in XP docking with different charge model of ligands.

\section{Molecular dynamics (MD) simulation}

MD simulations were performed using Desmond with OPLS 2005 force field [25]. Prepared structures were imported in Desmond setup wizard, and they were solvated in the orthorhombic periodic box of TIP3P water molecules and neutralized using an appropriate number of counter ions and $0.15 \mathrm{M}$ of salt concentration. A distance of $10 \AA$ Á was set between the box wall and protein complex to avoid direct interaction with its own periodic image. Steepest descent method was used to minimize the energy of prepared systems with a maximum of 5000 steps until a gradient threshold $(25 \mathrm{kcal} / \mathrm{mol} / \AA \hat{)})$ is reached. The systems were equilibrated using the default protocol provided in Desmond. The equilibrated systems were further carried to perform MD simulations for 20000 ps at a constant temperature of $300 \mathrm{~K}$ and the constant pressure of $1 \mathrm{~atm}$ with a time step of $2 \mathrm{fs}$.

\section{RESULTS AND DISCUSSION}

\section{Molecular docking and binding free energy calculation}

The prepared protein structure of IKK $\beta$ was docked using glide with nine compounds taken for the study. The results of the docking studies were provided in Table 1, and it is revealed that Morin as better compound based on docking score. All docking results are monitored by scoring functions that predict how well the ligand binds in a particular docked pose. This scoring function will give the ranking of the ligands. In the present study, docking score was taken into consideration for the selection of best ligand. It is an empirical scoring function that approximates the ligand binding free energy. It includes various force field interactions such as electrostatic and van der Waals contributions which influence ligand binding [26-28]. Subsequently, the docked structures were carried for binding free energy calculation. The results of binding free energy calculation were provided in Table 2. It is found that binding energy values were well supporting the docking result. Morin, salubrinal, icariin, and chondroitin sulfate have higher binding energy than other compounds. All the other values contribute to the $\Delta \mathrm{Gbind}$, thereby reflects the total binding energy of the protein-ligand complex.

\section{Binding pose analysis}

The binding mode of the compounds with IKK $\beta$ showed that $\mathrm{H}$-bonds and salt bridges along with other non-bonded interactions were found to influence the interaction between the proteins and ligands. The two-dimensional diagram of protein-ligand interaction was shown in Fig. 1 whereas the three-dimensional view of the active site of proteinligand interaction was shown in Fig. 2. It is found from Table 3 that Arg20, Leu21, Thr23, Lys44, Glu61, Glu97, Cys99, Lys106, Asp145, Asn150, andAsp166 were actively involved in H-bond interaction with ligands. Each compound has different binding modes, which reflects the difference of interacting residues with different functional groups. Morin has better interaction than other compounds. Either Cys99 or Lys44 found predominantly in most of the complex except in $\beta$-ecdysterone whereas both found interacting with Morin. The results obtained from the molecular docking reveals the key interacting residues required for IKK $\beta$ inhibition.

\section{MD simulation}

MD simulations were performed to procure a better understanding of the dynamic behavior and stability of the protein-ligand complex. All the MD simulations were performed for 20000 ps. The change in the structural integrity was analyzed by calculating the RMSD and root

Table 1: Glide XP result of compounds under study

\begin{tabular}{lllll}
\hline $\begin{array}{l}\text { Compound } \\
\text { CID }\end{array}$ & $\begin{array}{l}\text { Compound } \\
\text { name }\end{array}$ & $\begin{array}{l}\text { Docking } \\
\text { score }\end{array}$ & $\begin{array}{l}\text { Glide } \\
\text { emodel }\end{array}$ & $\begin{array}{l}\text { Glide } \\
\text { energy }\end{array}$ \\
\hline 5281670 & Morin & -11.043 & -65.769 & -44.611 \\
5717801 & Salubrinal & -7.687 & -75.464 & -58.085 \\
5318997 & Icariin & -7.671 & -81.167 & -57.511 \\
24766 & Chondroitin & -7.531 & -58.703 & -47.349 \\
& sulfate & & & \\
68289 & Sesamol & -7.171 & -31.674 & -24.597 \\
68245 & Delphinidin & -7.078 & -60.993 & -40.615 \\
6918837 & LBH589 & -6.981 & -65.362 & -41.171 \\
10281 & Thymoquinone & -6.794 & -31.482 & -26.06 \\
101778163 & B-Ecdysterone & -6.387 & -52.778 & -40.423 \\
\hline
\end{tabular}

CID: Compound identifier, XP: Extra precision 
Table 2: Prime MM-GB/SA result of compounds under study

\begin{tabular}{|c|c|c|c|c|c|c|c|c|}
\hline $\begin{array}{l}\text { Compound } \\
\text { CID }\end{array}$ & $\begin{array}{l}\text { Compound } \\
\text { name }\end{array}$ & $\Delta \mathrm{G}_{\text {bind }}$ & $\Delta \mathrm{G}_{\text {bind }}$ coulomb & $\Delta G_{\text {bind }} v d W$ & $\Delta \mathrm{G}_{\text {bind }}$ Lipo & $\Delta \mathrm{G}_{\text {bind }}$ Hbond & $\Delta \mathrm{G}_{\text {bind }}$ Solv GB & $\Delta \mathrm{G}_{\text {bind }}$ covalent \\
\hline 5281670 & Morin & -67.041 & -18.604 & -34.288 & -35.215 & -1.755 & 22.864 & -0.042 \\
\hline 5717801 & Salubrinal & -78.105 & -12.153 & -55.322 & -40.684 & -0.762 & 30.057 & 0.758 \\
\hline 5318997 & Icariin & -69.211 & -20.536 & -52.020 & -44.319 & -1.588 & 42.812 & 6.441 \\
\hline 24766 & $\begin{array}{l}\text { Chondroitin } \\
\text { sulfate }\end{array}$ & -30.044 & 30.800 & -49.157 & -32.415 & -1.519 & 15.492 & 6.756 \\
\hline 68289 & Sesamol & -39.810 & -11.872 & -19.564 & -16.385 & -0.444 & 8.200 & 0.256 \\
\hline 6918837 & LBH589 & -60.215 & 100.386 & -30.392 & -52.303 & -3.761 & -80.093 & 5.948 \\
\hline 10281 & Thymoquinone & -60.783 & -6.798 & -24.210 & -38.931 & -0.247 & 7.151 & 2.252 \\
\hline 101778163 & B-Ecdysterone & -71.751 & -18.480 & -35.476 & -57.727 & -1.857 & 37.853 & 3.936 \\
\hline
\end{tabular}

CID: Compound identifier, GB/SA: Generalized-born/surface area

Table 3: Hydrogen bonds in all complexes with their distances

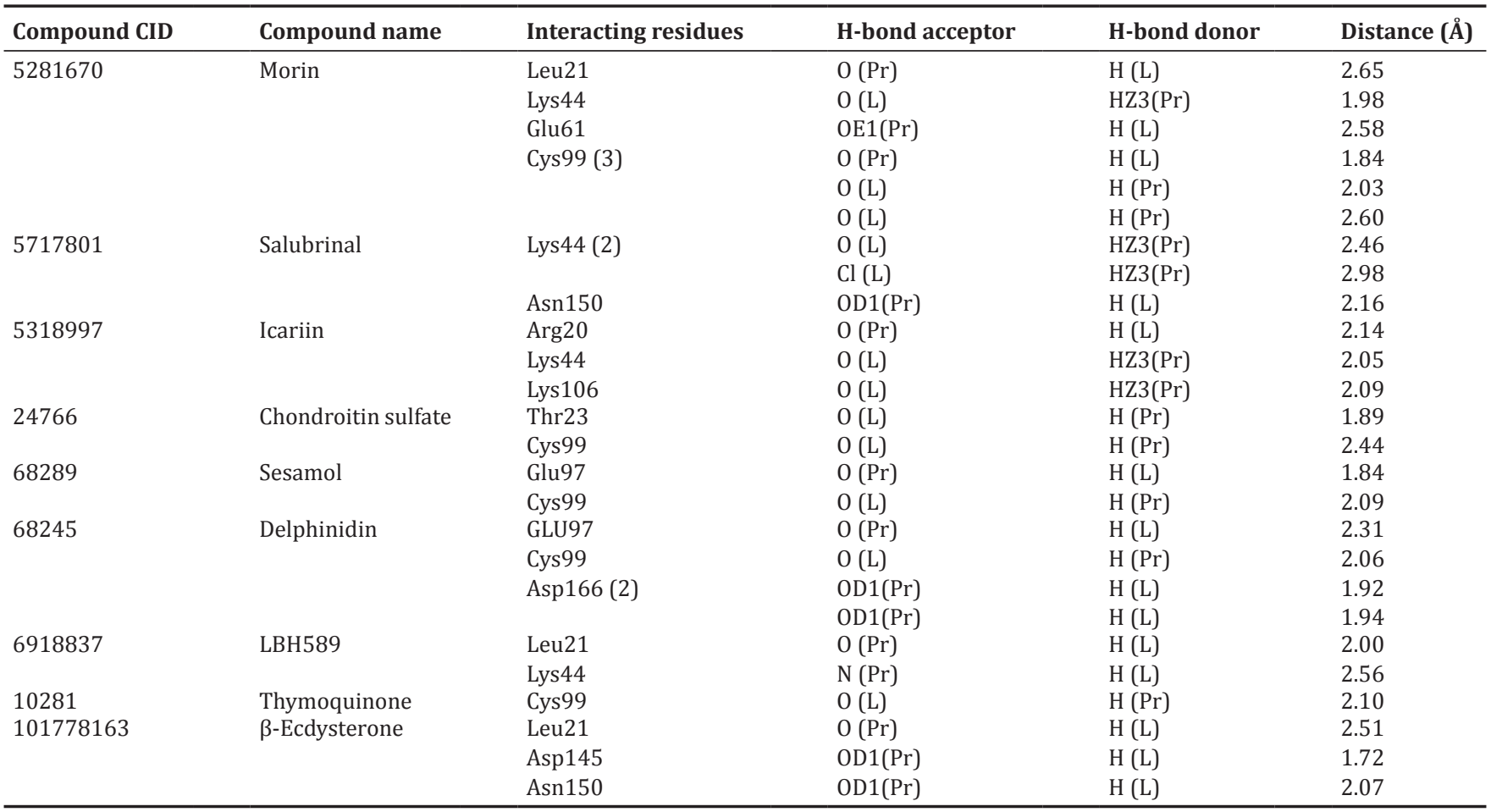

CID: Compound identifier

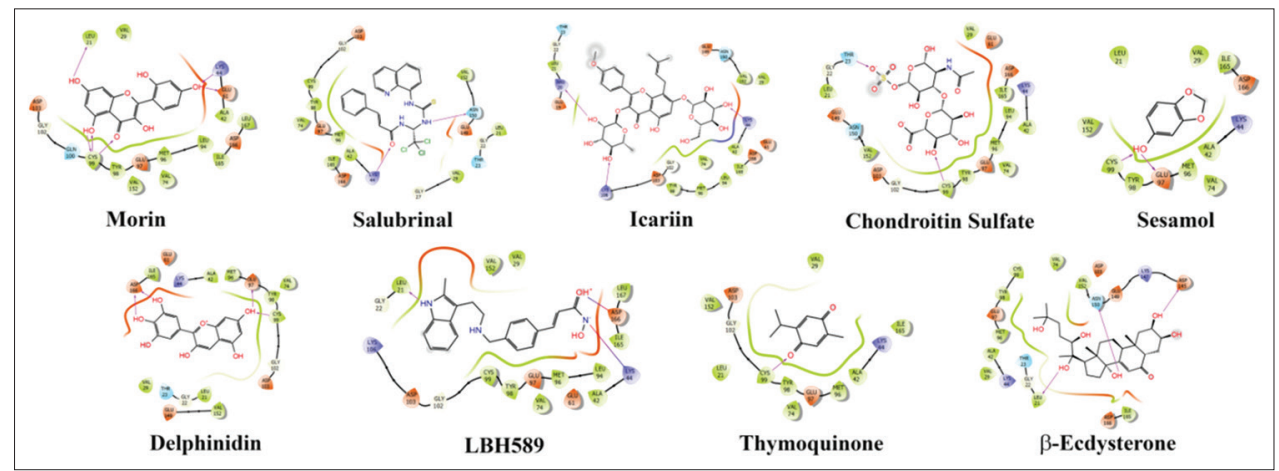

Fig. 1: Two-dimensional interaction diagram of an inhibitor of $\kappa \beta$ kinase subunit $\beta$ and its ligand complexes

mean square fluctuations (RMSF) over backbone atoms. Fig. 3 shows all the complexes have even deviations around $3 \AA$ and sometimes cross above $4 \AA \AA$. Fig. 4 shows RMSF of all residues in the protein on binding with five complexes. It shows salubrinal, and chondroitin sulfate fluctuates higher than the rest of the complexes, whereas Morin and icariin fluctuate higher than sesamol. Highest fluctuation of $25 \AA ̊$ was reached by the residues from 450 to 550 which were found to be the elongated chains. It was concluded from the trajectory analysis of all the protein-ligand complexes over 20000 ps time period of simulation that the ligand was stable in the binding pocket and did not dissociate 


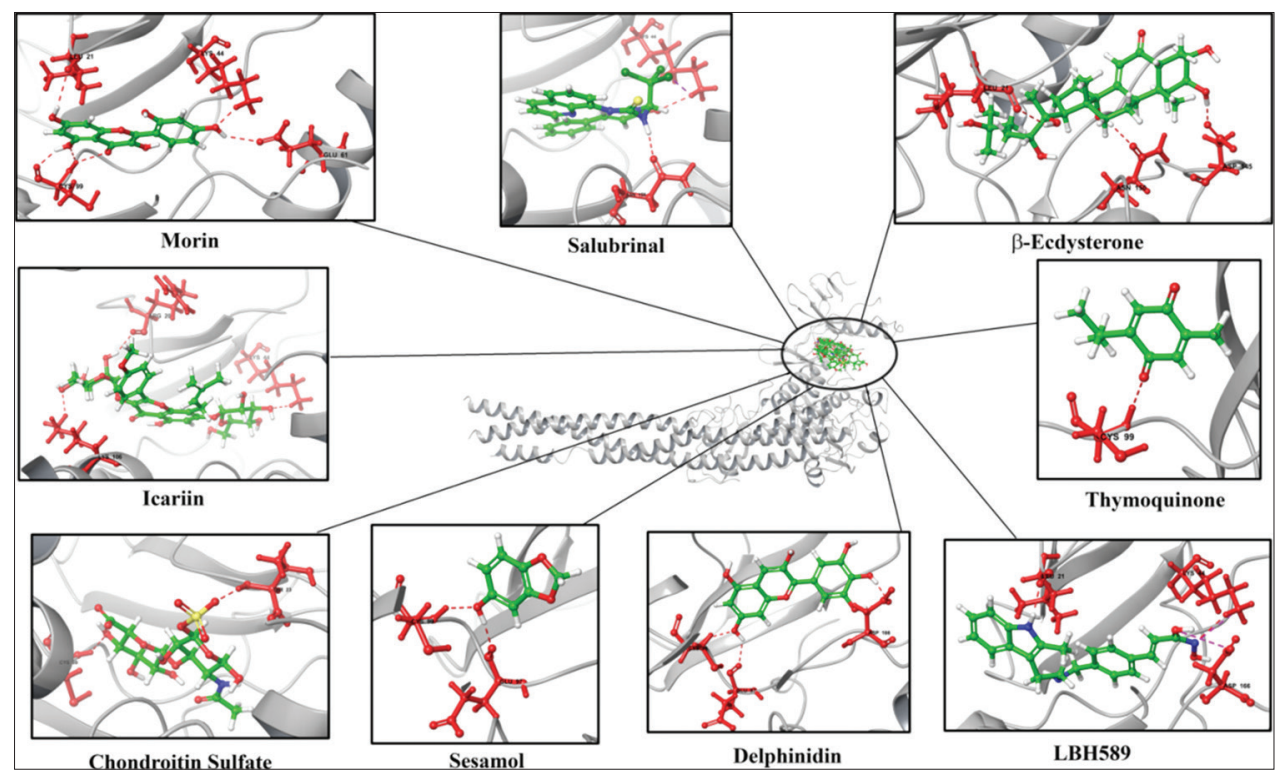

Fig. 2: Three-dimensional view of the active site of an inhibitor of $\kappa \beta$ kinase subunit $\beta$ and its ligand complexes

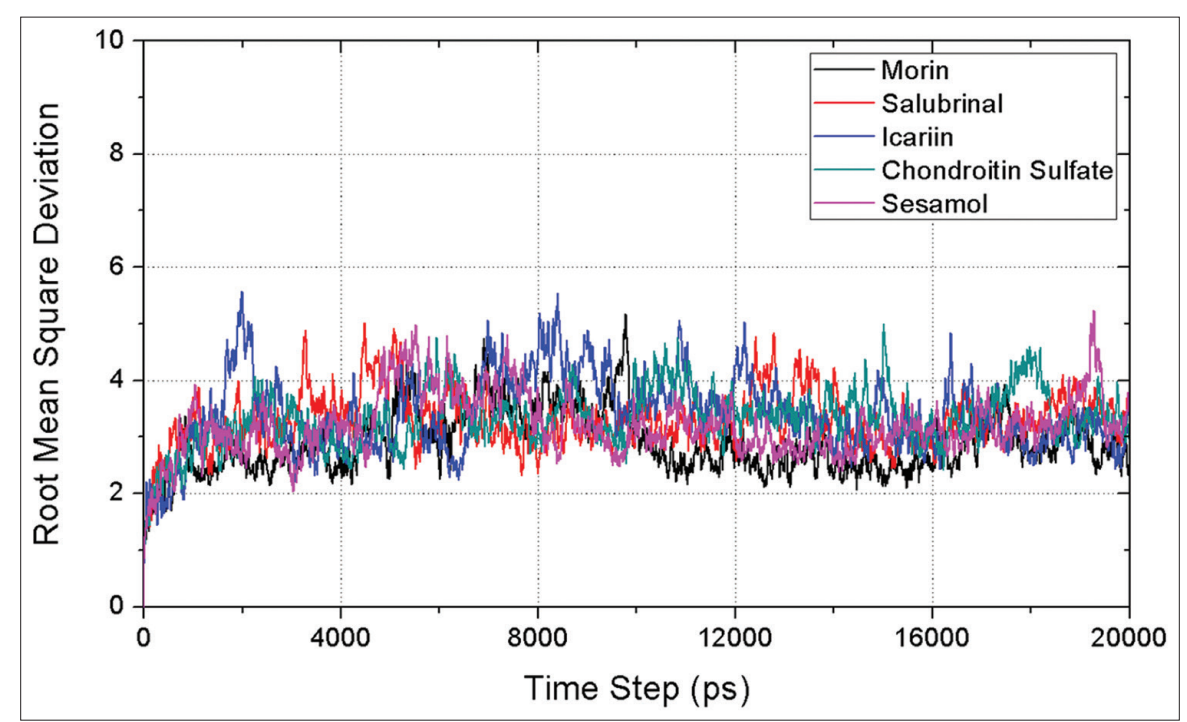

Fig. 3: Root mean square deviation of best five complexes over 20000 ps time period of simulation

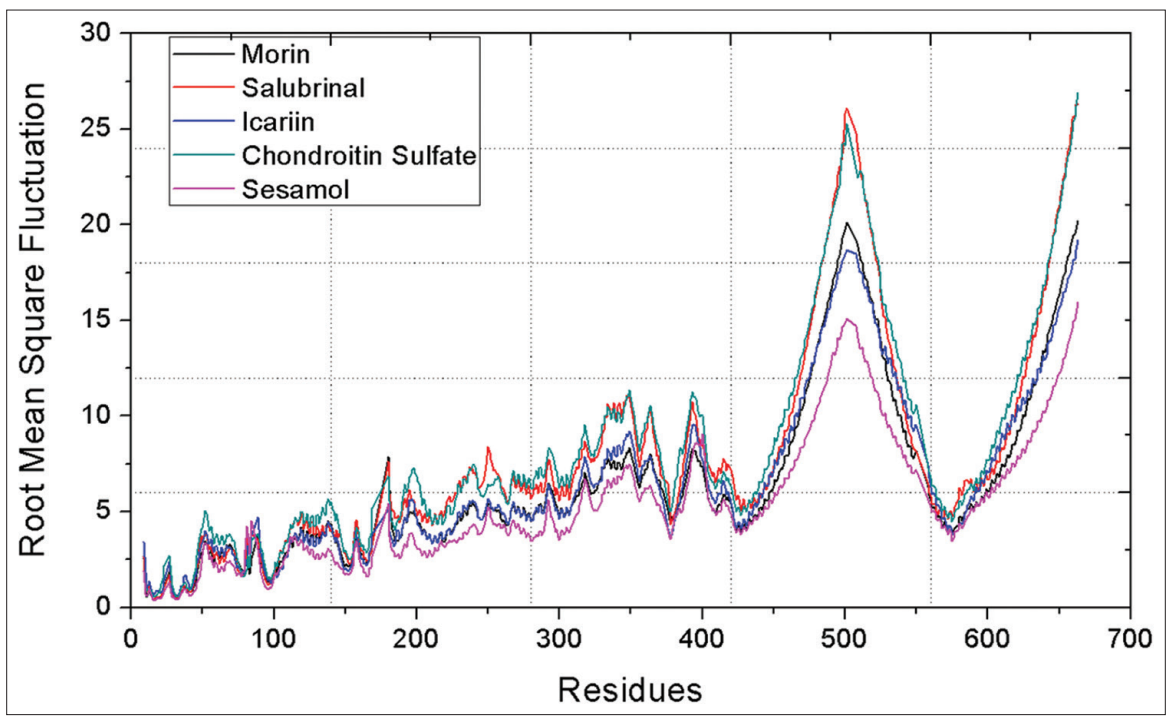

Fig. 4: Root mean square fluctuation of best five complexes over 20000 ps time period of simulation 


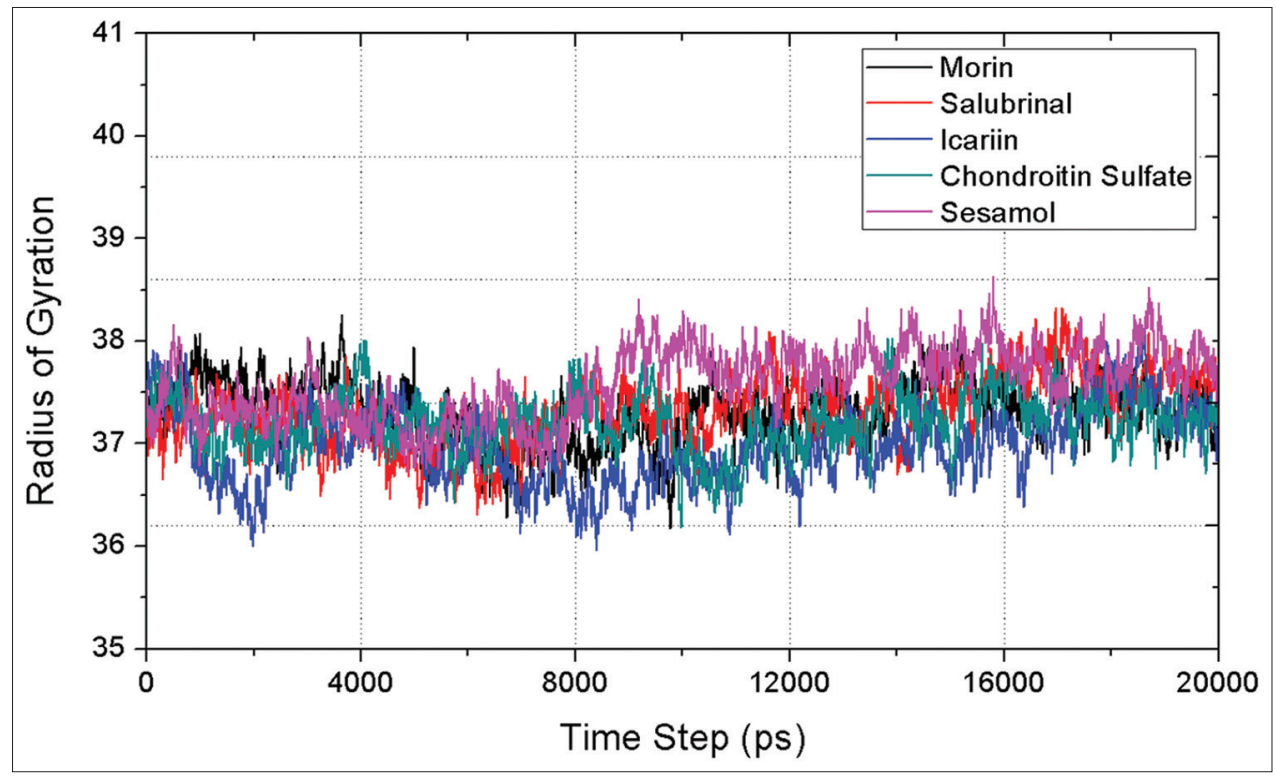

Fig. 5: Radius of gyration of best five complexes over 20000 ps time period of simulation

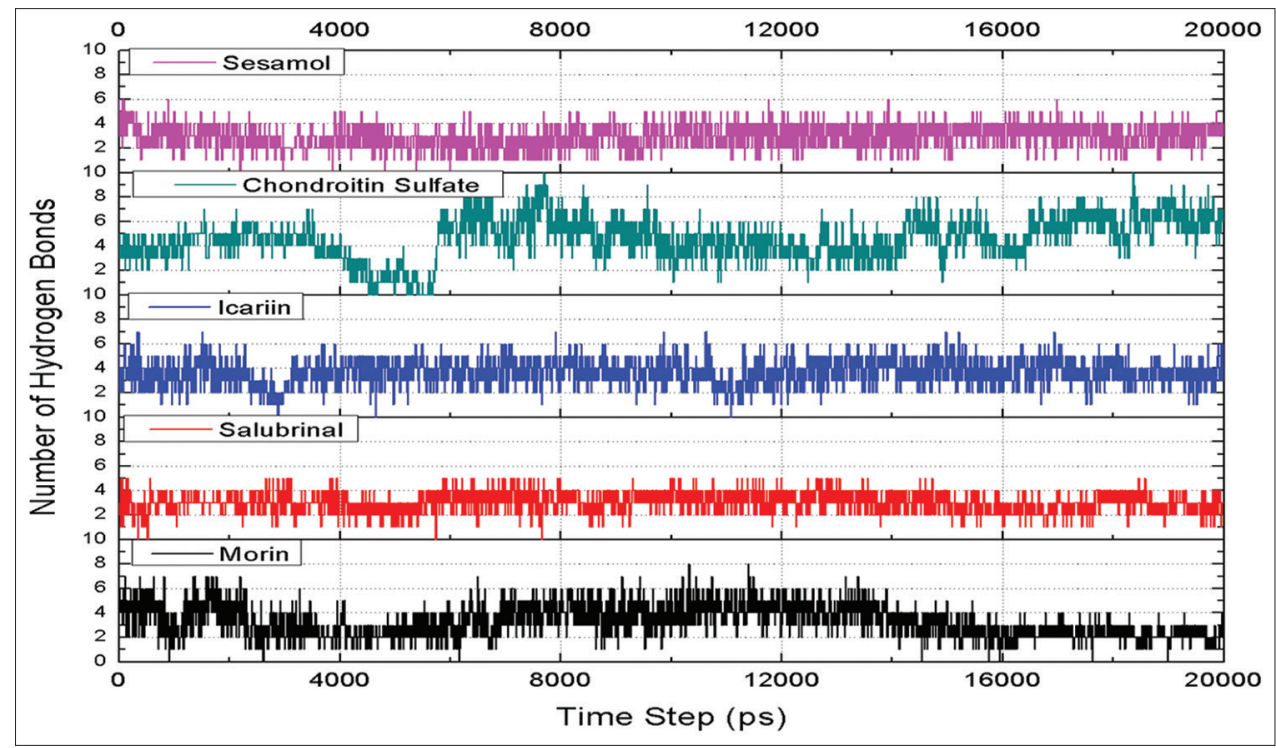

Fig. 6: Number of hydrogen bonds of best five complexes over 20000 ps time period of simulation

from the protein during the simulation. Further, the radius of gyration was calculated to predict the compactness of the protein-ligand complexes over the simulation time period, and the results were shown in Fig. 5. It was revealed that the all the protein-ligand complexes did not loss the compactness as the graph shows all the complexes were even with not many fluctuations. Fig. 6 shows the number of hydrogen bonds between the top 5 protein-ligand complexes which reveals that all the complexes have stable interaction expect in case of chondroitin sulfate where both loss and gain of more interaction happens during the simulation time period. Thus, the result obtained here confirms the structure and interaction stability of the protein-ligand complexes taken under study.

\section{CONCLUSION}

This in silico study revealed that NFK $\beta$ is suppressing medicinal herbal phytochemicals by inhibiting the MMP-13 production in chondrocytes through downregulation of $\mathrm{NF \kappa} \beta$ signaling pathways. In this study identified the best five compounds are Morin, salubrinal, icariin, and chondroitin sulfate, and sesamol. An in vitro study must be conducted to explore the IKK $\beta$ inhibitory potential of these five compounds. In addition, five bioactive compounds have been mentioned that may serve as promise therapeutic agent for the treatment of $\mathrm{OA}$.

\section{AUTHORS CONTRIBUTION}

Since there is only one author for this manuscript author contribution need not be mentioned.

\section{CONFLICTS OF INTEREST}

The authors have no conflict of interest.

\section{REFERENCES}

1. Scanzello CR, Goldring SR. The role of synovitis in osteoarthritis pathogenesis. Bone 2012;51:249-57.

2. Ulivi V, Giannoni P, Gentili C, Cancedda R, Descalzi F. P38/NF-Bdependent expression of COX-2 during differentiation and inflammatory response of chondrocytes. J Cell Biochem 2008;104:1393-406.

3. Marcu KB, Otero M, Olivotto E, Borzi RM, Goldring MB. NF- 
kappaB signaling: Multiple angles to target OA. Curr Drug Targets 2010;11:599-613.

4. Marcu KB, Otero M, Olivotto E, Borzi RM, Goldring MB. NFkappaB signaling: Multiple angles to target OA. Curr Drug Targets 2010;11:599-613.

5. Mariani E, Pulsatelli L, Facchini A. Signaling pathways in cartilage repair. Int J Mol Sci 2014;15:8667-98.

6. Paul S, Das AP, Bhattacharjee S. Rheumatoid arthritis: Molecular basis and cures from nature. Int J Pharm Pharm Sci 2015;7:30-9.

7. Chabib L, Awaluddin R, Ikawati Z, Martien R, Ismail H. Molecular docking, pharmacophore modelling, and adme-toxicity prediction of curcumin analog compounds as inflammatory inhibitor on rheumatoid arthritis. Int J Pharm Pharm Sci 2017;9:16-21

8. Chen WP, Wang YL, Tang JL, Hu PF, Bao JP, Wu LD. Morin inhibits interleukin- $1 \beta$-induced nitric oxide and prostaglandin $\mathrm{E} 2$ production in human chondrocytes. Int Immunopharmacol 2012;12:447-52.

9. Hamamura K, Lin CC, Yokota H. Salubrinal reduces expression and activity of MMP13 in chondrocytes. Osteoarthritis Cartilage 2013;21:764-72.

10. Zeng L, Wang W, Rong XF, Zhong Y, Jia P, Zhou GQ, et al. Chondroprotective effects and multi-target mechanisms of Icariin in IL-1 beta-induced human SW 1353 chondrosarcoma cells and a rat osteoarthritis model. Int Immunopharmacol 2014;18:175-81.

11. Stabler TV, Huang Z, Montell E, Vergés J, Kraus VB. Chondroitin sulphate inhibits NF- $\kappa B$ activity induced by interaction of pathogenic and damage associated molecules. Osteoarthritis Cartilage 2017;25:166-74.

12. Lu YC, Jayakumar T, Duann YF, Chou YC, Hsieh CY, Yu SY, et al. Chondroprotective role of sesamol by inhibiting MMPs expression via retaining NF- $\mathrm{KB}$ signaling in activated SW1353 cells. J Agric Food Chem 2011:59:4969-78.

13. Haseeb A, Chen D, Haqqi TM. Delphinidin inhibits IL-1 $\beta$ induced activation of $\mathrm{NF}-\mathrm{KB}$ by modulating the phosphorylation of IRAK-1Ser376 in human articular chondrocytes. Rheumatology 2013;52:998-1008

14. Wang JH, Shih KS, Wu YW, Wang AW, Yang CR. Histone deacetylase inhibitors increase microRNA-146a expression and enhance negative regulation of interleukin- $1 \beta$ signaling in osteoarthritis fibroblast-like synoviocytes. Osteoarthritis Cartilage 2013;21:1987-96.

15. Wang D, Qiao J, Zhao X, Chen T, Guan D. Thymoquinone inhibits IL-1 $\beta$-induced inflammation in human osteoarthritis chondrocytes by suppressing NF- $\mathrm{KB}$ and MAPKs signaling pathway. Inflammation
2015;38:2235-41

16. Zhang X, Xu X, Xu T, Qin S. $\beta$-Ecdysterone suppresses interleukin-1 $\beta$ induced apoptosis and inflammation in rat chondrocytes via inhibition of NF- $\kappa$ B signaling pathway. Drug Dev Res 2014;75:195-201.

17. Liu S, Misquitta YR, Olland A, Johnson MA, Kelleher KS, Kriz R, et al. Crystal structure of a human I $\mathrm{B}$ kinase $\beta$ asymmetric dimer. J Biol Chem 2013;288:22758-67.

18. Schrödinger, LLC. Schrödinger Release 2015-3: Maestro, version 10.3. New York, NY: Schrödinger, LLC; 2015.

19. Friesner RA, Banks JL, Murphy RB, Halgren TA, Klicic JJ, Mainz DT, et al. Glide: A new approach for rapid, accurate docking and scoring 1. Method and assessment of docking accuracy. J Med Chem 2004; $47: 1739-49$.

20. Singh N, Warshel A. Absolute binding free energy calculations: On the accuracy of computational scoring of protein-ligand interactions. Proteins 2010;78:1705-23

21. Lyne PD, Lamb ML, Saeh JC. Accurate prediction of the relative potencies of members of a series of kinase inhibitors using molecular docking and MM-GBSA scoring. J Med Chem 2006;49:4805-8.

22. Schrödinger, LLC. Schrödinger Release 2015-3: Prime, Version 4.1. New York, NY: Schrödinger, LLC; 2015.

23. Reddy KK, Singh SK, Tripathi SK, Selvaraj C, Suryanarayanan V. Shape and pharmacophore-based virtual screening to identify potential cytochrome P450 sterol 14 $\alpha$-demethylase inhibitors. J Rec Signal Transduct 2013;33:234-43.

24. Lyne PD, Lamb ML, Saeh JC. Accurate prediction of the relative potencies of members of a series of kinase inhibitors using molecular docking and MM-GBSA scoring. J Med Chem 2006;49:4805-8.

25. Ponder JW, Case DA. Force fields for protein simulations. Adv Protein Chem 2003;66:27-85.

26. Veeramachaneni GK, Raj KK, Bondili JS, Talluri VR. Screening and molecular docking studies of new natural agonists against peroxisome proliferator-activated receptor-alpha targeted to treat obesity. Asian J Pharm Clin Res 2016;9:80-4

27. Friesner RA, Murphy RB, Repasky MP, Frye LL, Greenwood JR, Halgren TA, et al. Extra precision glide: Docking and scoring incorporating a model of hydrophobic enclosure for proteinligand complexes. J Med Chem 2006;49:6177-96.

28. Gurula H, Loganathan T, Vashum Y, Pannerselvam S, Vetrivel U, Samuel S. In Silico screening of potent ppargamma agonists among natural anticancer compounds of indian origin. Asian J Pharm Clin Res 2016;9:320-4 